\title{
Research on Intelligent Supply Chain Management Under Unconventional Emergencies
}

\author{
Yonghui $\mathrm{CAO}^{1, \mathrm{a}}$, He JIANG*1,b \\ ${ }^{1}$ Department of Business Administration, Guangzhou College of Technology and Business, Guangzhou, China \\ * Corresponding author: He JIANG
}

\begin{abstract}
The harm of unconventional emergencies is increasingly prominent, which seriously restricts the sustainable development of society. Therefore, how to effectively deal with all kinds of unconventional emergencies and improve the ability of emergency management in the face of unconventional emergencies has attracted extensive attention from all walks of life. Therefore, the establishment of a sound emergency intelligent supply chain system is an important means to speed up the development of China's emergency industry and enhance the emergency support capacity of government. This paper mainly analyzes the problems existing in China's logistics system under unconventional emergencies, and puts forward the necessity and specific measures of introducing intelligent supply chain under unconventional emergencies.
\end{abstract}

\section{Introduction}

With the rapid development of China's social economy, various kinds of natural disasters, accident disasters, public health events and social security and other fields of unconventional emergencies have become increasingly prominent, seriously restricting the sustainable development of society. Therefore, how to effectively deal with all kinds of unconventional emergencies and improve the ability of emergency management in the face of unconventional emergencies has attracted extensive attention from all walks of life. The outbreak of a novel coronavirus pneumonia in 2020 also posed challenges for the emergency management of unconventional emergencies[1]. Since the outbreak of SARS in China in 2003, all walks of life in China have paid more and more attention to the design of emergency plan and the construction and research of emergency management system for various unconventional public emergencies. In January 2006, the State Council issued the national overall emergency plan for public emergencies and the national emergency plan for natural disaster relief. In June of the same year, the State Council issued the opinions on Comprehensively Strengthening emergency management. Subsequently, the relevant national departments and provinces and cities have also held emergency management meetings, and established emergency management agencies and issued emergency plans for different emergencies. The law of the people's Republic of China on response to public emergencies, a basic law in the field of emergency management, was officially issued in November 2007. The establishment of emergency management legal system shows the formation of emergency management framework in China[2].
The National Natural Science Foundation of China (NSFC) launched the major research plan of "unconventional emergency management research" in 2008. The number of NSFC in emergency field from 2011 to 2016 is shown in Figure 1.

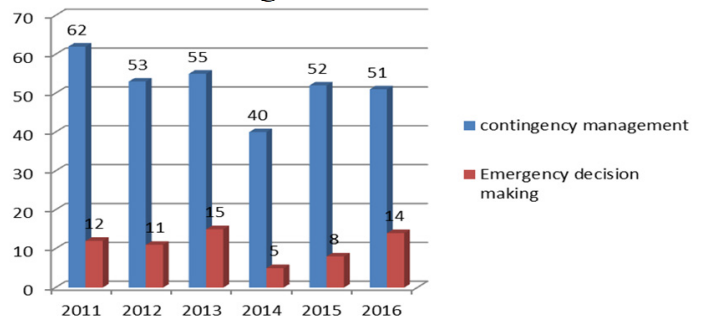

Fig1. number of NSFC in emergency field from 2011 to 2016.

Scholars generally believe that unconventional emergencies refer to emergencies with insufficient precursors, potential secondary hazards and serious destructiveness, which are difficult to deal with by conventional management methods. It has the characteristics of explosiveness (difficult to predict), evolution uncertainty and group diffusion, which is more likely to cause social concern. The remarkable characteristics of unconventional emergencies, such as unconventionality, uncertainty, uncontrollability, and serious social harmfulness, determine that the emergency decision-making process of unconventional emergencies is different from that of conventional emergencies[3-4].

As the main tool of social group communication and information diffusion, Internet provides conditions for unconventional emergency information decision-making. With the extensive and in-depth application of cloud computing, artificial intelligence and other information technologies, supply chain is deeply integrated with the Internet and Internet of things, and supply chain management has entered a new stage of intelligent supply 
chain. At present, the understanding of smart supply chain is not unified. It is generally accepted that smart supply chain combines modern information technology and management on the basis of traditional supply chain. It is an integrated system built within and between enterprises, which can realize the intellectualization, digitization, networking and automation of the supply chain. Compared with the traditional supply chain, smart supply chain is driven by demand and has stronger technology penetration. It emphasizes information sharing and interaction with customers and suppliers. Smart supply chain, as the application of "Internet plus" in the supply chain, can allocate emergency resources badly needed in unconventional emergencies, and reduce the economic and social losses caused by unconventional emergencies[5]. Based on this, this paper mainly studies the emergency management of intelligent supply chain under unconventional emergencies. It is an urgent task and an important research topic for Chinese academia and government to establish a scientific and reasonable emergency resource supply system and provide emergency resource allocation services to disaster emergency points.

\section{Literature research on Unconventional Emergency Management}

The main theoretical principles of Unconventional Emergency Management in the West originated from European and American countries. First, it is the black swan theory. Second, it is comprehensive crisis management theory. As the rudiment of crisis system management, comprehensive crisis management is considered as a whole, and a closed-loop crisis management mode is proposed. On this basis, the diamond model of crisis management in the later stage is formed. Third, it is the integrated disaster evolution theory. Fourth, it is crisis decision theory. After entering the new century, the crisis decision-making of unconventional emergencies has formed two main schools on the basis of the classical crisis decision-making theory: one is the optimal decisionmaking school which uses the methods of applied mathematics, operational research and cost analysis to study crisis decision-making. The other is to use mental simulation, scenario planning, transaction cost and nonlinear analysis to study the non-optimal decisionmaking school of crisis decision-making.

The research on unconventional emergencies in China originated from SARS in 2003. At present, the emergency management system has been initially established. The emergency management system has also changed from single disaster prevention and mitigation to comprehensive and systematic emergency management. Although China's emergency management system has played an important role in reducing crisis losses. However, novel coronavirus pneumonia and other unconventional emergencies have encountered great challenges. In the face of this situation, emergency management is the main way to deal with unconventional emergencies, and its basic theory research and management system construction have become the focus of current crisis management scholars. At present, there are three perspectives and approaches to the study of Unconventional Emergency Management in China: first, the basic theoretical research of unconventional emergencies; second, the emergency decision-making research of unconventional emergencies; third, the research on the emergency system and mechanism of unconventional emergencies. This paper mainly studies the emergency decision-making under unconventional emergencies, that is, resource allocation decision-making and management of intelligent supply chain in unconventional emergencies.

\section{Problems in China's emergency logistics control system under unconventional emergencies}

In recent years, China's emergency logistics rescue system has been significantly improved. Although great progress has been made in the response speed of emergency logistics and the orderly regulation of disaster relief arrangements, there are also some shortcomings

\section{1 the operation mechanism of emergency logistics under unconventional emergency situation needs to be improved}

The so-called operation mechanism should be long-term, instructive and operable. For emergencies, in January 2006, the State Council issued the national overall emergency plan for public emergencies. Subsequently, a number of special plans and departmental plans were formulated. The total number of emergency plans at all levels has reached millions. For emergency logistics, a unified leadership, classified coordination, territorial management based management system is being formed. However these are often guidance documents. From the perspective of emergency command, there is no strong coordination and command organization. The participating departments often act on their own, lack of coordination, and do not form an effective connection. In particular, the problem of poor information communication is the most prominent.

\section{2 the command ability of emergency logistics under unconventional emergency situation is insufficient}

After the occurrence of public emergencies, there is an urgent need for a large number of first-aid materials, which brings a great test to the emergency logistics. This requires the participation of multiple departments and channels. At this time, the phenomenon of multi leadership often occurs. For example, the novel coronavirus pneumonia occurred in Wuhan this year, and the allocation of relief supplies was a problem, which had a great impact on the initial rescue. This not only affects the effective operation of professional rescue forces, but also causes unnecessary risks and casualties. Therefore, 
the order control of emergency logistics system needs to be strengthened; in terms of distribution, it is necessary to improve the distribution system of relief materials. Through the coordination of the government emergency management department, the medical rescue materials are handed over to the professional logistics company for operation and configuration, and the government department will give appropriate command. Finally, the efficient allocation of medical rescue materials was realized, which played a positive role in the alleviation of the epidemic.

\section{3 emergency logistics technology shortage under unconventional emergency situation}

Logistics technology includes logistics transportation, storage and transportation, network communication and other facilities and equipment, such as hardware and information, operation technology standards and other software. At present, there are still some deficiencies in the infrastructure of emergency logistics in China. There are also barriers to operating techniques. The information system needs to be improved, and there is a lack of early warning and evaluation system. After the occurrence of public crisis, only by relying on accurate information, we can reasonably arrange information flow, people flow, capital flow and logistics, so as to realize seamless docking.

\section{4 lack of supervision mechanism for emergency logistics under unconventional emergency situation}

Because the emergency logistics emphasizes the timeliness, it must respond quickly to ensure the efficient and timely supply of emergency materials. The supervision and control in this case is easy to be ignored. After the event, the focus is on the results, and the evaluation system of emergency logistics is not enough attention, such as the quality of goods in the process of emergency logistics, transportation quality evaluation, disaster loss assessment after the event, summary of emergency logistics work, etc. The lack of supervision mechanism will directly lead to the blindness, nonstandard and uneconomical operation of emergency logistics, and even some immoral and disciplinary problems. These will bring uncertainties to the efficient operation of emergency logistics. To sum up, in order to solve these problems in the emergency logistics control system under unconventional emergencies in China, this paper attempts to apply the idea of intelligent supply chain management to the emergency management of public emergencies from the perspective of intelligent supply chain, so as to reduce or even eliminate some adverse effects and realize the rapid and efficient emergency logistics.

\section{Possibility of smart supply chain introduction under unconventional emergencies}

Smart supply chain has an important impact on the effectiveness of disaster relief under the emergency situation.

First, information integration and sharing are stronger. With the help of intelligent information network, the intelligent supply chain can effectively break the heterogeneity of the information system of the internal members of the supply chain, realize seamless docking, integrate and share the information within the supply chain. Rescue organizations can communicate with each other at any time, and the performance of the supply chain will not be significantly reduced with the increase of the supply chain level, and the scalability will be greatly enhanced.

Second, it is more collaborative. Under the highly integrated information mechanism, the internal organization of supply chain can better understand the information of other members. They timely grasp the internal and external information of the supply chain, contact the upstream and downstream organizations at any time in view of changes, make appropriate adjustments, and better cooperate, so as to improve the performance of the supply chain. Supply chain collaboration is the core and key of enterprise supply chain management. The stronger the synergy effect is, the more meaningful the supply chain management will be.

Third, the visualization features are more obvious. Smart supply chain tends to use visual forms such as pictures and videos to represent data, and uses intelligent and mobile means to access data. With the introduction of Internet technology, collaborative enterprises in the whole supply chain can share information, the bullwhip effect is alleviated and the disaster relief efficiency is improved.

\section{Construction of intelligent supply chain emergency management for unconventional emergencies}

\section{1 enhance the coordination mechanism and play the leading role of core enterprises in the smart supply chain}

From the perspective of collaborative management, it mainly includes organization collaboration, process collaboration and information collaboration. The task of organizational collaboration is to establish the organization of the emergency supply chain, and clarify the roles, objectives, responsibilities, rights and obligations of all parties involved. Process collaboration includes mobilizing all the participants, adjusting the structure of emergency supply chain at any time according to the process of emergency rescue and the dynamic changes of emergency concerns, and constantly improving the business process and restructuring work. It is the direct embodiment of emergency efficiency. Information collaboration strives to achieve efficient information interaction between the main bodies of each node in the emergency supply chain, so as to avoid errors and other problems, and realize the effective allocation of emergency resources. Among the three relationships, 
organizational collaboration is the foundation; business collaboration is the main body, and the key lies in information collaboration.

In addition, the realization of emergency logistics management system is to enable the emergency logistics management to be carried out orderly, so that emergencies can be effectively solved. Therefore, we must play a leading role in the smart supply chain. The core enterprises in the supply chain not only have the economic and technical strength to dominate the supply chain process, but also have a strong influence on the production and marketing decisions of node enterprises in the supply chain. It plays a leading role in the whole supply chain operation. It can basically reflect the overall performance level of the whole supply chain. This is the key to smart supply chain management.

\section{2 establish a special emergency command center to give full play to the function of intelligent supply chain in unconventional emergencies}

Establish a national and unified emergency command center. Emergency management mainly focuses on departments. It is responsible for the command and coordination of disaster relief work throughout the country. The unified emergency command center is equivalent to the core enterprise of the whole emergency intelligent supply chain. The establishment of it is conducive to the integration and sharing of supply chain information, and to the coordination of other departments to achieve the purpose of unified action. In terms of resource management, it can effectively integrate and rapidly allocate resources. At the same time, it is necessary to improve the ability of government cooperation and enterprise participation, and give full play to the agile response function of intelligent supply chain in unconventional emergency situation. After the occurrence of emergency, the government of the former place will encounter many difficulties in dealing with the emergency separately. This requires the assistance of other governments to provide corresponding materials and personnel. In addition, enterprises should also improve their awareness of social responsibility and actively participate in the handling of emergency events.

\section{3 strengthen the construction of information sharing technology and hardware, and build efficient logistics information network}

We should establish efficient emergency logistics information network, including the establishment of integrated command network, transportation information network, storage information network and so on. The construction of information network center can consider relying on the government public information platform to establish a perfect network platform for emergency logistics public information. The central leading organization, subsystems, relevant departments at all levels of the government and all kinds of logistics centers or enterprises participating in the emergency logistics command system can realize information exchange and sharing on the platform. It is an authoritative platform for the government to release information to the public and an effective way for the public to feedback information to the government. From the perspective of supply chain, we should also emphasize the continuous collaboration in the whole process. Therefore, it is necessary to improve the ability of information intake and feedback, so as to ensure the efficiency and fluency of information, and implement tracking decision and dynamic command. If the coordination is out of balance or destroyed, it should be adjusted and restored quickly. In order to establish and improve the emergency logistics information guarantee plan, we should fully consider all kinds of possibilities, and strive to make the plan more scientific and operable. In the whole process of dealing with emergency events, the participants should be able to share information and improve the ability of information interaction.

\section{4 control before and during doing good deeds, and build a sound emergency logistics supervision and evaluation mechanism}

We should do a good job in the control of emergency logistics before and after the unconventional emergencies. Among them, the part of pre control mainly deals with the problem of emergency material prediction. According to the characteristics of unconventional emergencies, a variety of control decision-making methods are considered. For example, "scenario response" method, case-based reasoning (CBR) based emergency material demand forecasting method is commonly used. Through the establishment of case-based reasoning emergency material demand forecasting model, the decision-making base is formed. At the same time, we should do a good job in supervision and control, and give full play to the supervision function of unconventional emergencies.

After the rescue, the relevant government departments should evaluate the whole incident handling process and form an evaluation report. A set of performance evaluation indicators should be established and reasonable methods should be selected to evaluate the overall implementation effect, operation process and performance of each node member in the emergency supply chain. Through the evaluation, it can help the decision-makers to identify the problems existing in the operation, so as to improve and improve continuously. The risk and reliability of the emergency supply chain should also be evaluated, including risk identification, risk level assessment, establishment and calculation of reliability evaluation index system, so as to help decision makers master the implementation effect of emergency supply chain in an all-round way.

\section{Conclusion}

Under the unconventional emergency, there is a higher requirement for the allocation of resources such as relief materials. Therefore, it is an important task to establish a perfect emergency intelligent supply chain system and strengthen the emergency management ability of our 
country (China). This is also an important topic in the field of supply chain research. Strengthening the emergency intelligent supply chain management is an important means to speed up the development of China's emergency industry and enhance the emergency support ability of government. Emergency intelligent supply chain management is an effective way to improve the ability of emergency supply support, and also an important way to reduce the total cost of emergency supply chain. Intelligent supply chain management under unconventional emergencies is a new theoretical and practical problem. It is of great significance to reduce the cost of emergency supply chain and improve the efficiency of emergency supply chain.

\section{Acknowledgment}

This work is financially supported by outstanding scholars of philosophy and Social Sciences in Henan Province higher education in 2018, 2018-YXXZ-06; Henan philosophy and Social Sciences Planning Project in 2019, 2019BJJ003; The social development project of Henan provincial key R \& D and promotion project (Science and technology tackling key problems) in 2019, project number: 515; The science and technology innovation talent support program project of Henan Province higher education (HUMANITIES AND SOCIAL SCIENCES) in 2017, 2017-cxrc-004; Foshan social science planning project in 2020, 2020-QN11. Thanks for the help.

\section{References}

1. Li A N, Deng X Q, Zhao Q H. Unconventional emergency organizational dynamic reconstruction based on fractal 8.12 Tianjin explosion case study[J]. Management Review, 2016, 28(8): 193-206.

2. Cui X M, Yao K. Contract construction in chaotic situation - Evidence from crisis management cases (2008-2013)[J]. Economic Theory and Business Management, 2014(11): 72-81.

3. Li JH, Zhou YC, Shang W, etc. A cloud computation architecture for unconventional emergency management WAIM 2013 Workshops (EMI3D'2013), LNCS 7901,2013, 6,.187-198.

4. Han Z Y, Wong W G, Zhang W, et al. Backgrounds, targets, and organization of the major research plan "study on unconventional emergencies management"[J]. Bulletin of National Natural Science Foundation of China, 2009, 23(4): 215-220.

5. CHUNG B D, KIM S I, LEE J S. Dynamic supply chain design and operations plan for connected smart factories with additive manufacturing [J]. Applied sciences, 2018, 8 (4) : 583 - 598. 